\title{
EAHP European Statements baseline survey 2015: first steps on the implementation journey
}

\author{
Joan Peppard, ${ }^{1,2}$ Petr Horák, ${ }^{3}$ Nicholas Gibbons, ${ }^{4}$ Jonathan Underhill ${ }^{4}$
}

\begin{abstract}
${ }^{1}$ European Association of Hospital Pharmacists, Brussels, Belgium

${ }^{2}$ Pharmacy Department, Midland Regional Hospital Tullamore, Tullamore, Offaly, Ireland

${ }^{3}$ Hospital Pharmacy, University Hospital Motol, Prague, Czech Republic

${ }^{4}$ Keele University Centre for Medicines Optimisation, Keele University, Keele, Staffordshire, UK
\end{abstract}

\section{Correspondence to} Joan Peppard, European Association of Hospital Pharmacists, Brussels 1040, Belgium; joan.peppard@hse.ie

Received 19 January 2016 Revised 26 January 2016 Accepted 27 January 2016 Pharm 2016;23:76-79.

\section{ABSTRACT}

An implementation plan was developed in conjunction with the publication of the European Statements of Hospital Pharmacy. Subsequently a baseline survey on the status of the Statements was conducted with specific questions on awareness, capability and capacity seen as crucial to informing future implementation plans. The baseline survey showed that, 18 months after agreement at the European Summit of Hospital Pharmacy, hospital pharmacists across Europe have a growing awareness of the Statements. There is a significant variation across Europe with awareness levels ranging from $100 \%$ to less than $30 \%$. Capacity within European Healthcare systems to achieve implementation is challenging with less than 10\% of respondents in most countries indicating sufficient capacity to implement the services described in the Statements. Staff skills and experience to implement the changes was identified by respondents at less than $20 \%$ in many countries. The implementation plan will need to be constantly updated and modified to sustain progress.

\section{BACKGROUND}

The European Statements of Hospital Pharmacy, ${ }^{1}$ agreed in May 2014, create a vision of hospital pharmacy services that will significantly advance the health and well-being of patients in European hospitals. These 44 statements in six overarching topic areas, are based on a consensus among healthcare providers and patients on the role of hospital pharmacists as part of a multidisciplinary collaborative team approach providing optimal care for patients. ${ }^{2} 3$ This team approach provides pharmacists with an opportunity to contribute their expertise in medication use to improve patient outcomes. ${ }^{4}$ The Statements are important because by describing services and activities that support the safe and effective use of medications, through the action of hospital pharmacists, there is a road map that can be followed in the interest of patient care and patient outcomes in European health systems. The vision that is the European Statements of Hospital Pharmacy is to drive commitment and action to improve the care of patients and is applicable to all European health systems, regardless of the differences that exist in the provision of services. ${ }^{5}$ The practice environment envisioned by the European Statements of Hospital Pharmacy is one in which pharmacists spend most of their time working collaboratively with other healthcare providers to manage complex patient medication concerns. $^{6}$

\section{INITIAL STEPS}

To use a map, one has first to be aware of its existence and second be prepared to follow the planned route. After the 2014 European Summit of Hospital
Pharmacy concluded, an implementation plan was developed by the European Association of Hospital Pharmacists (EAHP). The initial focus was an awareness campaign to develop an understanding of the statements and the potential impact of improved patient care that would result from the services described in the Statements. The campaign employed social media along with presentations at conferences, national and international, as well as documenting good practice initiatives that could be shared between hospitals and between countries. ${ }^{7}$ The categories for entry into the extensive poster exhibition at the annual EAHP Congress were changed to reflect the six topic areas outlined in the Statements. Existing annual education seminars were refocused on capability of staff to deliver the services required with the first revised academy seminar presented on Medication Reconciliation using a 'train the trainer' model in October 2015. ${ }^{8}$

The implementation plan includes measures to assess progress over time. The implementation of the Statements is to be by assessed by asking Heads of Departments of Pharmacy to complete an annual survey. Previous surveys on the status of European hospital pharmacy, undertaken every 5 years, had provided a wealth of information on European hospital pharmacy practice but were considered to be too time consuming and expensive to be practical as a measure of ongoing change. ${ }^{9}$ The new version of the surveys are planned with a revolving focus on the six sections of the European Statements of Hospital Pharmacy while questions on awareness and readiness for implementation are to be included each year. The baseline survey was conducted in spring 2015 and the results are described in the article by Horák et al. ${ }^{10}$

\section{SURVEY QUESTIONS}

Specific questions on awareness and preparedness to assist with the further development of the implementation plan were included as follows;

1. The pharmacists within our hospital are aware of the 44 European Statements of Hospital Pharmacy

2. The pharmacists within our hospital agree in principle with the Statements

3. Our hospital has the capability ${ }^{\mathrm{i}}$ to implement all of the Statements now

4. Our hospital has the capacity ${ }^{\mathrm{ii}}$ to implement all of the Statements now

${ }^{i}$ Capability. Does the organisation have the staff with the right skills and experience to support the change effort?

${ }^{i i}$ Capacity. Does the organisation have sufficient numbers of people or time to undertake the change? 


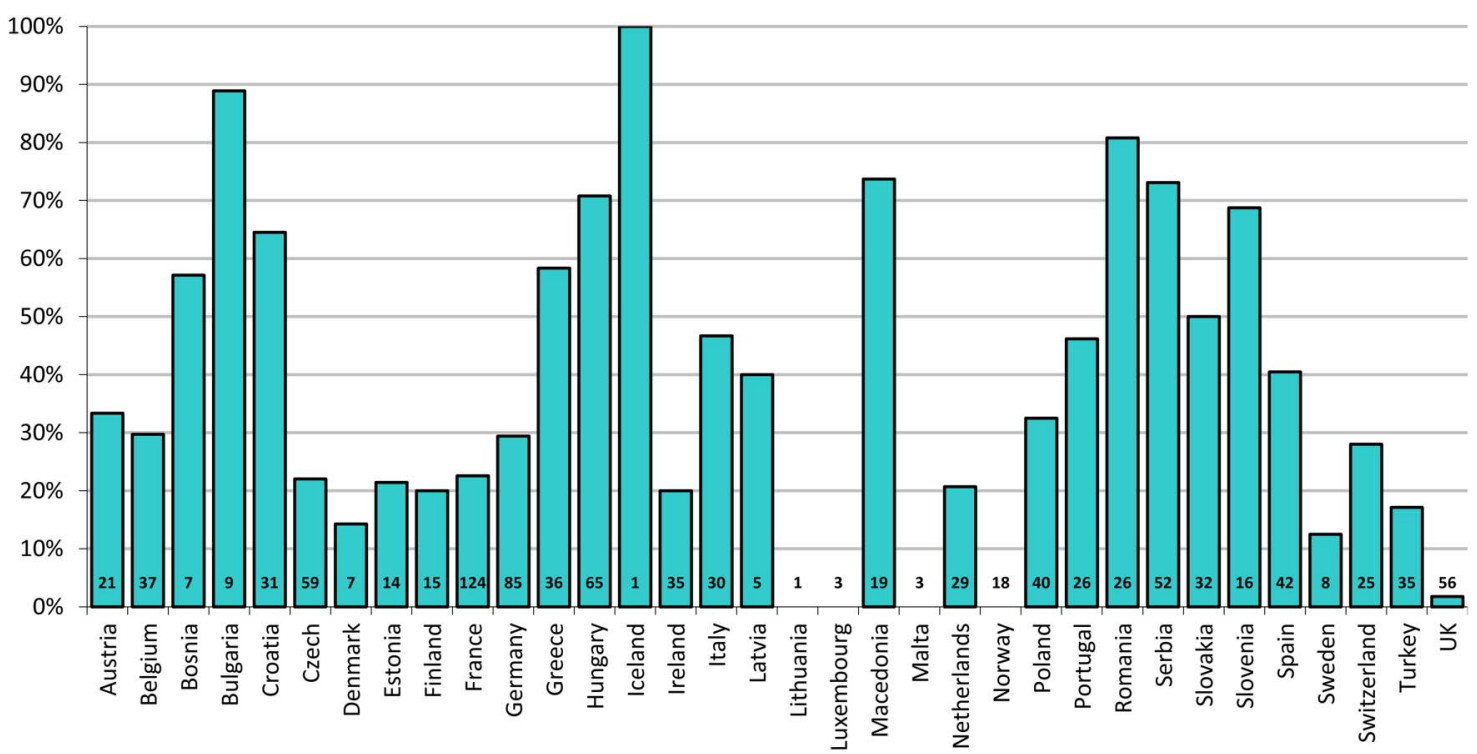

Figure 1 Percentage of respondents who agree with the statement 'The pharmacists within our hospital are aware of the 44 European Statements' of Hospital Pharmacy.

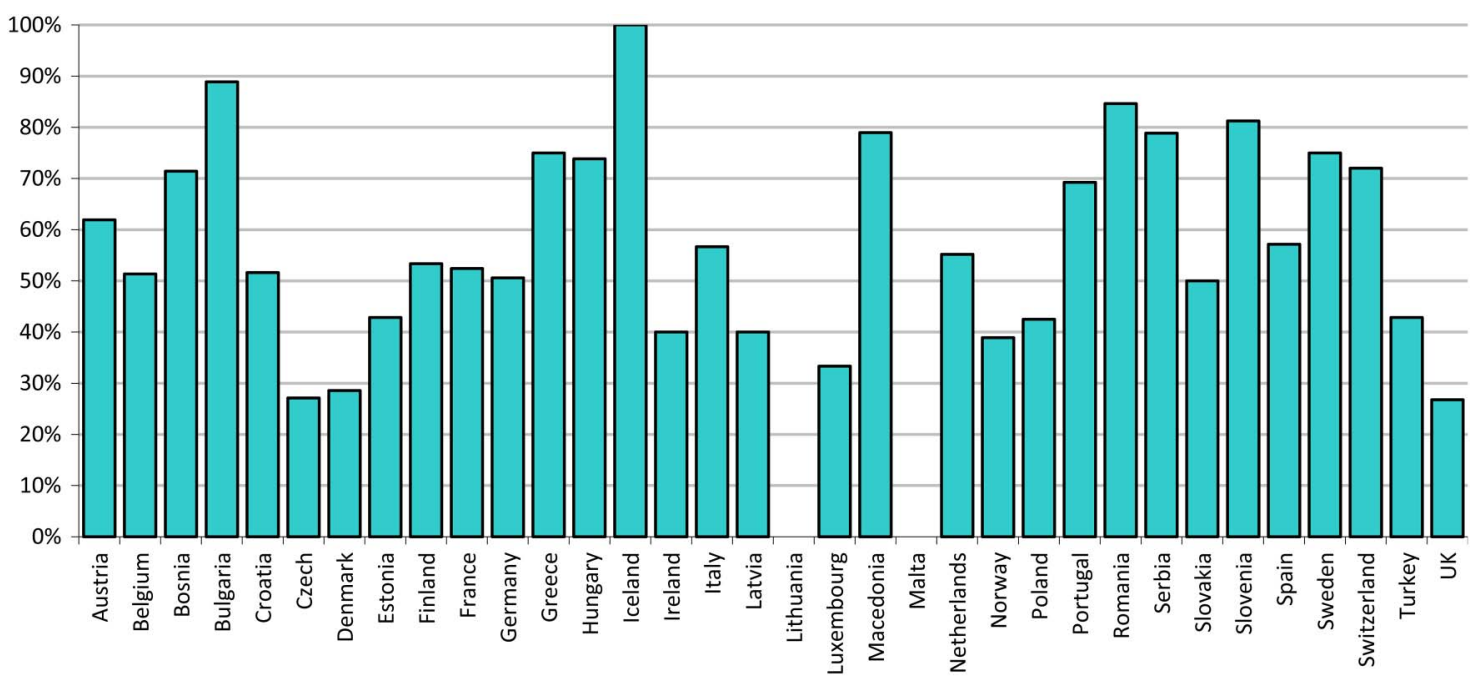

Figure 2 Percentage of respondents who agree with the statement 'The pharmacists within our hospital agree in principle with the Statements'.

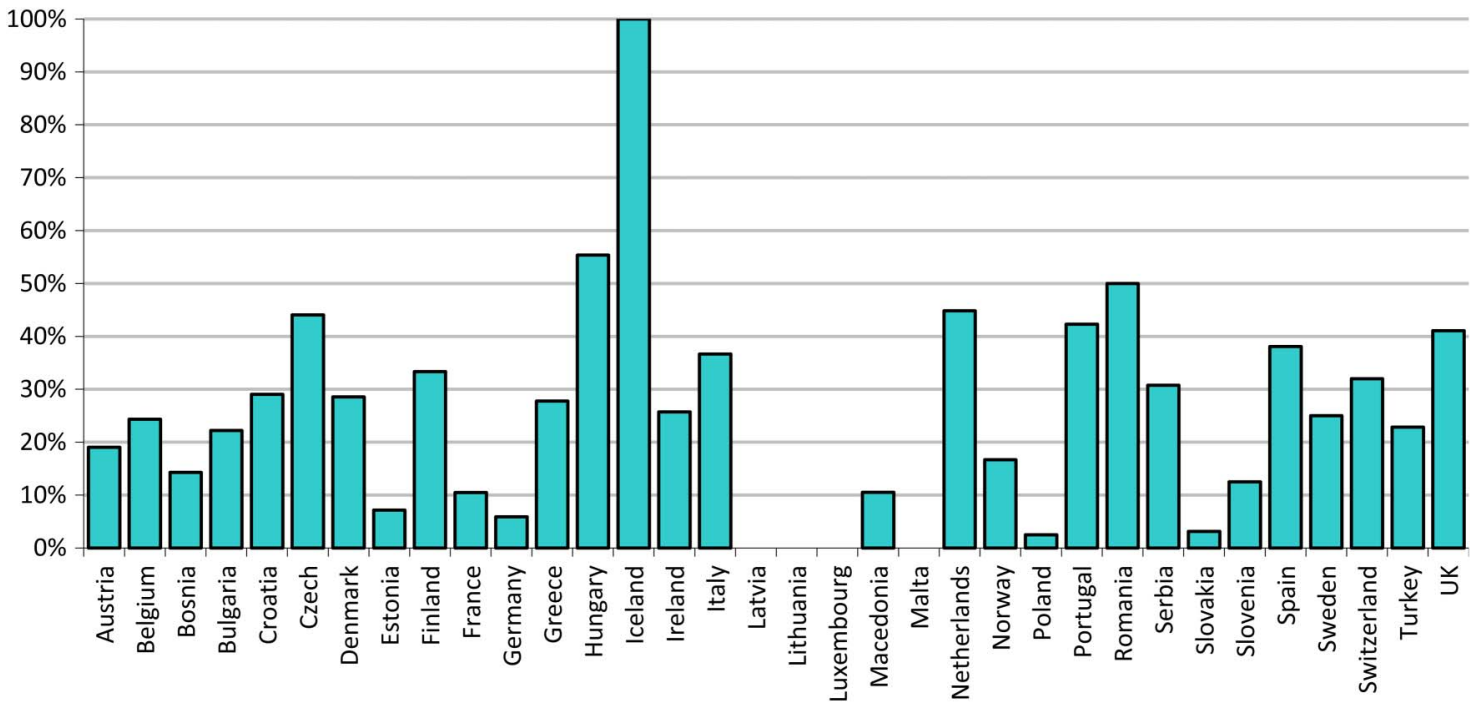

Figure 3 Percentage of respondents who agree with the statement 'Our hospital has the capability to implement all of the Statements now.' 


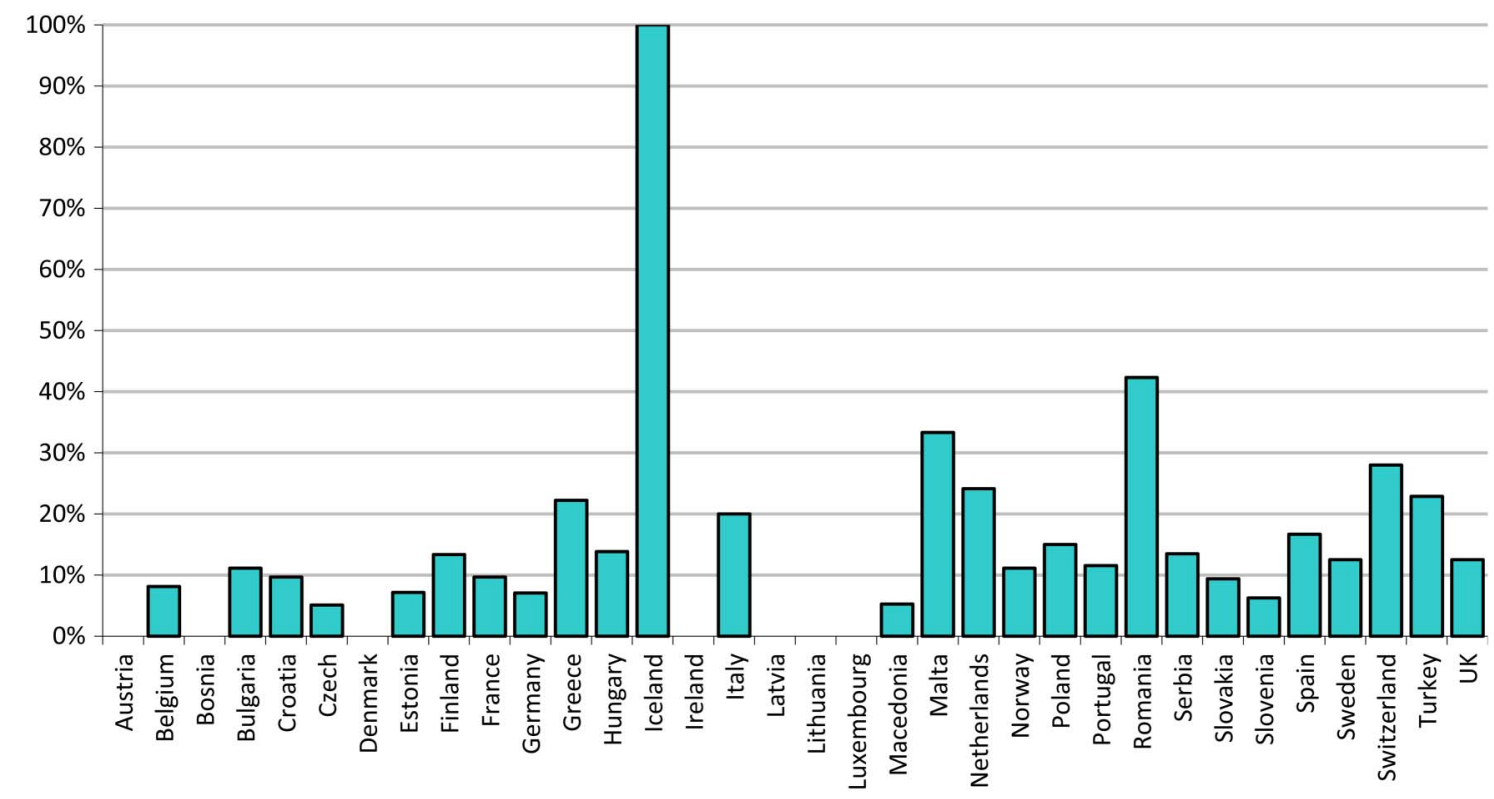

Figure 4 Percentage of respondents who agree with the statement 'Our hospital has the capacity to implement all of the Statements now'.

\section{RESULTS}

The results of the baseline survey show that awareness, as estimated by the Department Heads, varies considerably across Europe. The estimated awareness level per country is shown in figure 1 . At 18 months since the launch this is a generally positive result and is in line with expectations. However the lack of awareness in larger countries that have advanced hospital pharmacy clinical practice such as the UK and The Netherlands requires further attention and modification of the implementation plan. The number of responses per country is also shown in figure 1.

It is encouraging to note the broad acceptance of the European Statements of Hospital Pharmacy as a vision of patient focused hospital pharmacy services as seen in figure 2. This confirms the consensus reached at the European Summit on Hospital Pharmacy in May 2014.

Of more concern is that preparedness for implementation was regarded by the respondents with regard to capability and capacity were low. Capability was defined in the survey as

Does the organisation have staff with the right skills and experience to support the change effort?

Having the appropriate skills was considered by the implementation group and will be addressed in part by the provision of post graduate education, such as the EAHP Academy Seminars, which lend themselves to reproducibility at country level.

Capacity was defined for the survey as

Does the organisation have the sufficient number of people or time to undertake the change?

Capacity was considered by the survey respondents to be minimal and this would be in accordance with the 5-year surveys previously undertaken by EAHP that showed a low pharmacy staffing compliment in many European hospitals.

\section{FUTURE DEVELOPMENTS}

The EAHP implementation group will modify the implementation strategy on an ongoing basis in view of the information provided by the annual survey. The strategy will continue to plan for increased awareness of the European Statements of Hospital Pharmacists by pharmacists and to demonstrate the appropriateness of the strategy through education and sharing of best practice. The implementation strategy will be further developed to assist Heads of Pharmacy in convincing senior management in European Hospitals of the merits and viability of the strategy in the interest of patient care and patient outcomes. The implementation group, with the assistance of the members and delegates to the General Assembly, will continue to increase awareness, acceptance and implementation of services designed to meet the vision described in the European Statements of Hospital Pharmacy. This is a marathon, not a sprint, and the assistance of each European hospital in completing the annual online survey to measure change and see how well they are progressing with the project's goals will be essential to the process.

\section{CONCLUSION}

The initial phase of the implementation process has achieved a significant awareness among European pharmacists about the European Statements of Hospital Pharmacy. The implementation process is on-going and a continuous fine tuning, adjusting, and responding to each individual country needs will be required as implementation continues.

\section{Key messages}

Awareness of the European Statements of Hospital Pharmacy is increasing.

- There is limited capacity in European hospitals to provide the pharmacy services required to implement the Statements.

- An amended implementation plan will be required to address these findings.

Today is not yesterday; how can our works and thoughts, if they are always to be the fittest, continue always the same? Change, indeed, is painful, yet ever needful.

- Thomas Carlyle 
Acknowledgements The authors wish to thank all members of the EAHP survey group; Petr Horak, Chairperson, Tadja Gala, Juraj Sykora, Joan Peppard. The authors also thank all hospital pharmacists who participated in the EAHP survey undertaken in Spring 2015.

Contributors All authors made a substantial contribution to the conception or design of the survey described in the article. JU and NG contributed the analysis and interpretation of data; JP and PH drafted the article and revised for content; JP had final approval of the version to be published.

Competing interests None declared.

Provenance and peer review Not commissioned; internally peer reviewed.

Data sharing statement Additional data from the survey will be published elsewhere in the journal.

\section{REFERENCES}

1 The European Statements of Hospital Pharmacy. Eur J Hosp Pharm 2014;21:256-8.
2 Maskrey N, Underhill J. The European Statements of Hospital Pharmacy: achieving consensus using Delphi and World Café methodologies. Eur J Hosp Pharm 2014;21:264-6.

3 Batista A, Preece D. Forming the initial European Statements of Hospital Pharmacy. Eur J Hosp Pharm 2014;21:259-61.

4 Kim MM, Barnato AE, Angus DC, et al. The effect of multidisciplinary care teams on intensive care unit mortality. Arch Intern Med 2010;170: 369-76.

5 Frontini R. The statements: a reflection on the results. Eur I Hosp Pharm 2014;21:270-5.

6 Preece D. The European Statements of Hospital Pharmacy: the perspective of EAHP members. Eur J Hosp Pharm 2014;21:279-81.

7 Neef C. Good practice initiatives. Eur J Hosp Pharm 2014;21:282-4.

$8 \mathrm{http}: / /$ www.eahp.eu/events/academy/EAHP-Academy-Seminars

9 EAHP's surveys of hospital pharmacy practice across Europe. http://www.eahp.eu/ publications/surveys

10 Horák P, Peppard J, Sýkora J, et al. EAHP European Statements baseline survey 2015: results. Eur J Hosp Pharm 2016;23:69-75. 